ARTICLE

\title{
Highly active and efficient catalysts for alkoxycarbonylation of alkenes
}

Kaiwu Dong ${ }^{1, \star}$, Xianjie Fang ${ }^{1, \star}$, Samet Gülak ${ }^{1}$, Robert Franke $^{2,3}$, Anke Spannenberg$^{1}$, Helfried Neumann ${ }^{1}$, Ralf Jackstell ${ }^{1} \&$ Matthias Beller ${ }^{1}$

Carbonylation reactions of alkenes constitute the most important industrial processes in homogeneous catalysis. Despite the tremendous progress in this transformation, the development of advanced catalyst systems to improve their activity and widen the range of feedstocks continues to be essential for new practical applications. Herein a palladium catalyst based on 1,2-bis((tert-butyl(pyridin-2-yl)phosphanyl)methyl)benzene L3 (py ${ }^{t} b p x$ ) is rationally designed and synthesized. Application of this system allows a general alkoxycarbonylation of sterically hindered and demanding olefins including all kinds of tetra-, tri- and 1,1-disubstituted alkenes as well as natural products and pharmaceuticals to the desired esters in excellent yield. Industrially relevant bulk ethylene is functionalized with high activity (TON: >1,425,000; TOF: $44,000 \mathrm{~h}^{-1}$ for initial $18 \mathrm{~h}$ ) and selectivity (>99\%). Given its generality and efficiency, we expect this catalytic system to immediately impact both the chemical industry and research laboratories by providing a practical synthetic tool for the transformation of nearly any alkene into a versatile ester product.

\footnotetext{
${ }^{1}$ Leibniz-Institut für Katalyse e.V. an der Universität Rostock, Albert-Einstein Straße 29a, Rostock 18059, Germany. ${ }^{2}$ Evonik Performance Materials GmbH, Paul-Baumann-Straße 1, Marl 45772, Germany. ${ }^{3}$ Lehrstuhl für Theoretische Chemie, Ruhr-Universität Bochum, Bochum 44780, Germany. ${ }^{\star}$ These authors contributed equally to this work. Correspondence and requests for materials should be addressed to M.B. (email: matthias.beller@catalysis.de).
} 
F unctionalization reactions of alkenes constitute a fundamental basis of today's chemical industry. Hence, in addition to polymerizations and oxidations, carbonylation reactions count among the largest industrial applications in the area of homogeneous catalysis and a large variety of value-added bulk and fine chemicals are available via this technology ${ }^{1-5}$. Besides hydroformylations and related transformations ${ }^{6-8}$, which produce over 10 million tons of oxo products every year, alkoxycarbonylation is another important type of such reactions. They have been shown to be core processes for the production of acids, esters and amides ${ }^{3-5,9}$. For example, the current state-of-the-art commercial process (Lucite Alpha process) to methyl propionate, a key intermediate for methyl methacrylate polymers, is produced based on the palladium-catalysed methoxycarbonylation of ethylene on a $>300,000$-ton-perannum scale ${ }^{10,11}$.

Comparing the reactivity of diverse olefins involving transition metal hydride complexes, it is well known that ethylene shows highest activity and terminal olefins react much faster than internal ones. Hence, the rate of the respective functionalization reaction falls with increasing steric hindrance of the substrate ${ }^{12-16}$. With respect to catalytic carbonylations the reactivity order of different olefins was found to be independent of the metal $\mathrm{Co}^{17}$, $\mathrm{Rh}^{18}$ or $\mathrm{Pd}^{19}$ (Fig. 1). In fact, the reaction of branched olefins requires significantly more severe reaction conditions or alternatively more active catalysts. Essentially, the carbonylation of tetra- or tri-substituted $s p^{2}$-configurated C-atoms is extremely difficult (Keulemans' rule) ${ }^{20}$. Accordingly, catalytic carbonylation reactions are limited to terminal olefins and the $\mathrm{n}, \mathrm{m}$-disubstituted internal alkenes $\mathrm{R}^{1}-\mathrm{CH}=\mathrm{CH}-\mathrm{R}^{2}$. The major problem impeding the development of a general carbonylation of tetra- and trisubstituted alkenes is the low binding affinity of these substrates towards the metal center and the sluggish migratory insertion of the metal complex leading to intrinsically demanding hydrometalation ${ }^{21}$. The resulting tertiary alkylmetal intermediates are highly unstable and are readily converted back to the stable alkenes. Another challenge for such transformations is the formation of unwanted by-products such as alkanes (in the case of hydroformylation) and the corresponding ethers (in the case of alkoxycarbonylation) especially under acidic conditions. As a result, and to the best of our knowledge, no general and practical catalyst has yet been developed for the alkoxycarbonylation of tetra- and tri-substituted alkenes.

On the other hand, tetra- and/or tri-substituted alkenes are interesting feedstocks and this bond motif is frequently found in natural products, pharmaceuticals and petrochemicals. Interestingly, for several industrial bulk processes, pure $\alpha$-olefins are not available at an economically viable price. Therefore, mixtures are used including internal and branched olefins. As an illustrative example, so-called dibutene is a mixture of more $>30$ compounds including mainly octenes, methylheptenes, and dimethylhexenes. Notably, this feedstock is produced via dimerization of 1-butene and 2-butene on a 500,000-ton-perannum scale. Due to the low reactivity of sterically hindered internal olefins, a significant amount of this feedstock cannot be further functionalized, which leads to unwanted waste. Hence, the development of improved catalyst systems for the carbonylation of tetra- and tri-substituted alkenes is an important and rewarding but highly challenging task.

A scarcely explored possibility to valorize such 'inert' internal olefins would be a fast isomerization to more reactive alkenes. Unfortunately, despite the vast knowledge on isomerization reactions ${ }^{21}$, such catalyst systems, which operate under mild conditions in the presence of $\mathrm{CO}$, are not known. On the basis of our long-standing interest in this area ${ }^{22,23}$ as well as the elegant works of other groups ${ }^{24-28}$, we started to explore the development of a more efficient isomerization-carbonylation catalyst. In this regard, herein we report a rationally designed palladium catalyst, which allows for alkoxycarbonylations of both highly demanding alkenes and industrially relevant bulk olefins such as ethylene with unpreceded activity and selectivity.

\section{Results}

Reaction concept. To develop the first general alkoxycarbonylation catalyst for 'non-reactive' olefins, we focused on the alkoxycarbonylation of tetramethylethylene 1a as the benchmark substrate. In our initial attempts, we performed catalytic experiments with two state-of-the-art palladium catalysts: $\mathrm{Pd}_{2}(\mathrm{dba})_{3} / \mathbf{L} \mathbf{1} / \mathrm{MeSO}_{3} \mathrm{H}$ (refs 10,11,29) known from the methyl methacrylate process developed by Eastham et al. and established by Lucite International and the Shell system $\mathrm{Pd}(\mathrm{OAc})_{2} / \mathbf{L} 2 /$ $\mathrm{MeSO}_{3} \mathrm{H}$ pioneered by Drent and co-workers for the methoxycarbonylation of alkynes ${ }^{30-35}$. However, in both cases no carbonylation occurred and only the corresponding ether-resulting from electrophilic addition of methanol-was detected in 50 and $45 \%$ yield, respectively. Obviously, to realize the alkoxycarbonylation of $\mathbf{1 a}$, the development of a new catalyst system is imperative. According to the so-called hydride mechanism (see Supplementary Fig. 1 for details), successful alkoxycarbonylation requires the formation of a palladium hydride complex ${ }^{26,36-39}$.

After coordination of the alkene to this complex followed by migratory insertion into the $\mathrm{Pd}-\mathrm{H}$ bond, the corresponding alkyl complex is obtained, which is transformed into an acyl complex by the migratory insertion of CO. Finally, inter- or intramolecular nucleophilic attack of methanol on the acyl carbonyl leads to the formation of the desired ester and regeneration of the palladium hydride species. Notably in the presence of acid, the overall rate-limiting step associated with the highest energetic barrier is the alcoholysis of the Pd-acyl species $^{26,38}$.

As shown in Fig. 2, two key problems have to be solved to realize the desired alkoxycarbonylation of tetramethylethylene 1a: (1) the isomerization of the internal alkene to the more reactive intermediate $\mathbf{B}$ has to be enhanced under carbonylation conditions; (2) besides the irreversible alcoholysis of the Pd-acyl species, all other steps in the catalytic cycle are reversible. Hence, to shift the equilibrium towards the desired product and to avoid formation of $\mathbf{3 a}$, the alcoholysis of the final Pd-acyl species has to be accelerated markedly (step 5). This key step is known to be catalysed by base, which unfortunately impedes steps 1 and 3 . To solve this contradiction, we envisioned the inclusion of an amphoteric group as part of the catalyst systems. With this idea in

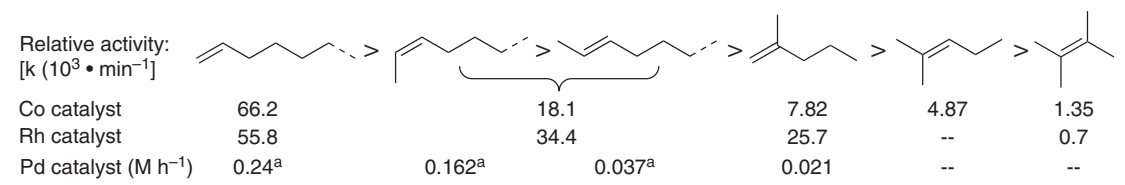

Figure 1 | Reaction rates of alkene carbonylations. ${ }^{a}$ Heptenes were used. 


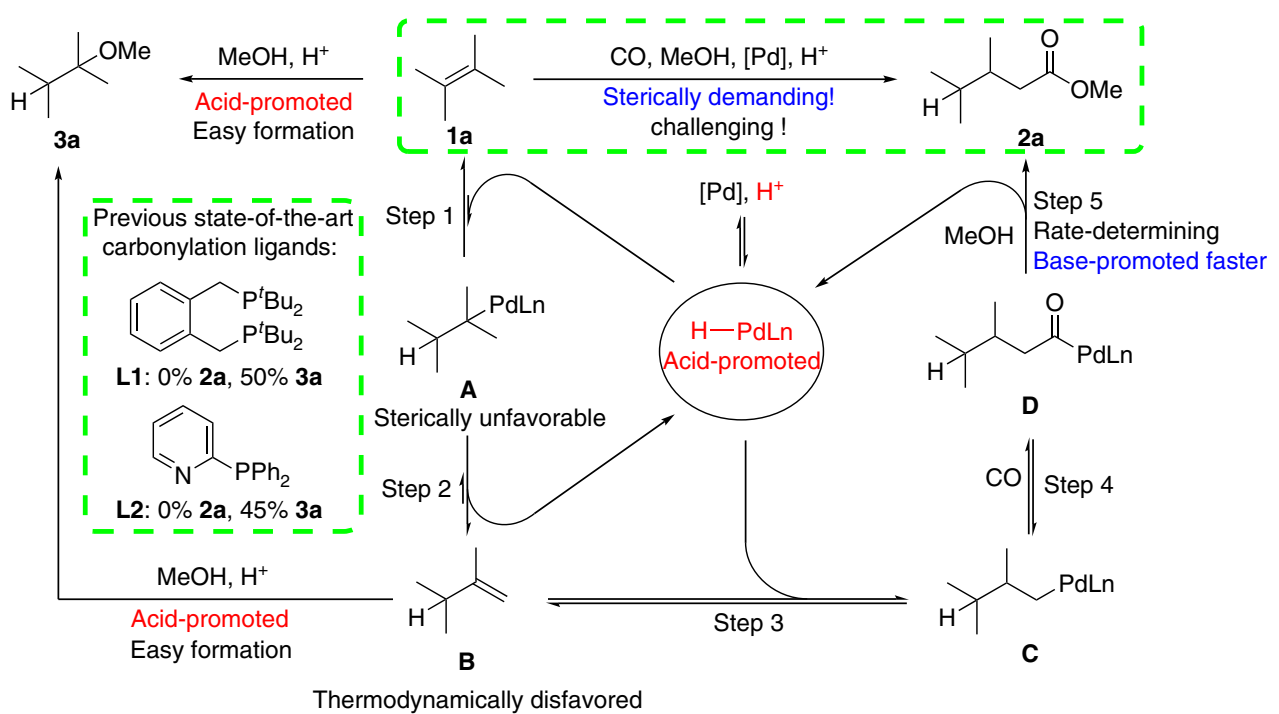

Figure 2 | Palladium-catalysed isomerization-methoxycarbonylation of tetramethylethylene. Required steps and challenges.

mind, the novel bidentate phosphine ligand $\mathbf{L} 3$ containing both sterically hindered and amphoteric groups on the P-atom was designed and synthesized (see Supplementary Figs 2-4 for details). Notably, the pyridine group in this ligand should act as a proton-shuttle for the alcohol, which facilitates the alcoholysis of the Pd-acyl species ${ }^{30-35}$. Structures of $\mathbf{L 3}$ and the corresponding palladium complexes were confirmed unambiguously by X-ray diffraction (Fig. 3). Both complexes $\operatorname{Pd}(\mathbf{L} \mathbf{3})(\mathrm{dba})$ and $\operatorname{Pd}(\mathbf{L} \mathbf{3})($ allylic)OTf contain only one ligand coordinated to palladium through the $\mathrm{P}$ atoms. The coordination geometry at the palladium atom can be best described as trigonal-planar for $\mathrm{Pd}(\mathbf{L} \mathbf{3})(\mathrm{dba})$ and pseudo-square-planar for $\operatorname{Pd}(\mathbf{L 3})$ (allylic)OTf (see Supplementary Figs 5-7 for details). The ${ }^{31} \mathrm{P}$ NMR spectra of these complexes in $\mathrm{CD}_{2} \mathrm{Cl}_{2}$ solution also indicate the clean formation of a single mono-ligated species.

To prove our concept, the methoxycarbonylation of tetramethylethylene 1a was performed in the presence of $\operatorname{Pd}(\mathbf{L} \mathbf{3})(\mathrm{dba})$ and $\operatorname{Pd}(\mathbf{L} \mathbf{3})($ allylic)OTf with $p$-toluenesulfonic acid monohydrate (PTSA) as co-catalyst under typical carbonylation conditions $\left(0.1 \mathrm{~mol} \% \mathrm{Pd}\right.$ catalyst, $\left.40 \mathrm{bar} \mathrm{CO}, 120^{\circ} \mathrm{C}\right)$. Indeed, the desired product 2a was afforded in almost quantitative yield. Similar results were obtained using the in situ-generated catalyst $\left(\operatorname{Pd}(\mathrm{acac})_{2} / \mathbf{L} 3 / \mathrm{PTSA}=0.1 / 0.4 / 1.6 \mathrm{~mol} \%\right)$, which demonstrates the superiority of this novel ligand compared with previously privileged ligands. To also compare the reactivity of other well-known ligands such as $\mathrm{PPh}_{3},{ }^{n} \mathrm{BuPAd}_{2}, \mathrm{dppb}$, dppf, Xantphos, and Naphos with our system, we investigated their effect in this challenging benchmark reaction (see Supplementary Fig. 8 for details). As shown in Fig. 3, none of the investigated monodentate and bidentate ligands provided any desired product (again only the corresponding ether by-product was obtained).

To improve the novel catalyst system further on, the effects of other critical reaction parameters such as Pd precursor, acid co-catalyst and $\mathrm{CO}$ pressure were investigated for the alkoxycarbonylation of $\mathbf{1 a}$ in the presence of $\mathbf{L 3}$ (see Supplementary Fig. 9 for details). Compared with $\mathrm{Pd}(\mathrm{acac})_{2}$, $\mathrm{Pd}(\mathrm{OAc})_{2}$ gave slightly better results under identical conditions. $\mathrm{PdCl}_{2}$ showed lower activity, which is attributed due to the strong coordination of the counterion. Zero-valent precursor $\mathrm{Pd}_{2}(\mathrm{dba})_{3}$ catalysed the methoxycarbonylation of $\mathbf{1 a}$ with comparable rate. Acid co-catalysts with strong acidity and non-coordinating anions facilitate the carbonylation of 1a (order of activity: $\mathrm{TfOH}>\mathrm{H}_{2} \mathrm{SO}_{4}>$ PTSA). The effect of CO pressure is negligible, while the reaction temperature has a noticeable influence on the rate of the methoxycarbonylation of $\mathbf{1 a}$.

Alkoxycarbonylation of various alkenes. With an optimal catalyst in hand, we investigated the scope and limitations for this system. Initially, alkoxycarbonylations of 1a with different alcohols were carried out. To our delight, primary as well as secondary alcohols such as ethanol, tetrahydrofurfuryl alcohol, and iso-propanol worked well and afforded the desired esters 4-6 in almost quantitative yield (see Supplementary Fig. 10 for details).

Next, various aliphatic and aromatic alkenes including internal and terminal ones were employed under the methoxycarbonylation conditions and afforded the desired esters in good to excellent yields (Fig. 4). In addition to 1a, tetra-substituted 9,10-octalin $\mathbf{1 b}$ was converted smoothly to $\mathbf{2} \mathbf{b}$ in high yield with excellent regioselectivity. To the best of our knowledge, this is the first example of alkoxycarbonylations of bicyclic internal olefins, which offers new valorization possibilities for such strained intermediates. Again, there is no ester observed when using L1 instead of $\mathbf{L} \mathbf{3}$, thus demonstrating the striking reactivity difference between the two systems. Aromatic olefins such as indene constitute suitable substrates and $2 \mathrm{c}$ was obtained in $96 \%$ yield with high regioselectivity. Simple cycloalkenes often show low reactivity under traditional alkoxycarbonylation conditions. Gratifyingly, they are methoxycarbonylated successfully into the corresponding esters $\mathbf{2 d}$ and $\mathbf{2 e}$ in almost quantitative yields within $2 \mathrm{~h}$ (see Supplementary Fig. 11 for details). Similarly, 1-methylstyrene and related derivatives as well as 1-vinylnaphthalene and 1,1-diphenylethylene were converted to the corresponding esters $\mathbf{2 f - k}$ in almost quantitative yields. Interestingly, diester $\mathbf{2 1}$, which has potential applications in the polymer chemistry, was also able to be obtained in $99 \%$ yield and selectivity through the dimethoxycarbonylation of 1,3-diisopropenylbenzene $\mathbf{1 l}$ using our catalytic system. When L1 was used in the carbonylation of alkenes of such kind, significantly lower yields of the desired esters and significant amounts of the corresponding ethers were observed due to the stability of the corresponding carbenium ion.

With respect to organic synthesis, this catalytic system is compatible with a broad range of functional groups. Indeed, alkenes containing electron-donating (triethylsilyl $\mathbf{1 m}$ ) as well as electron-withdrawing substituents (perfluoroalkyl $\mathbf{1 n}$, 


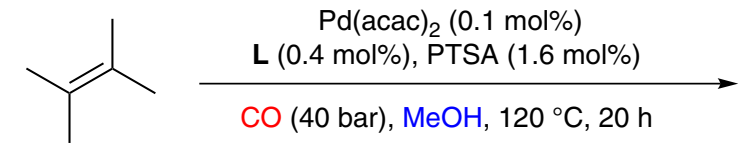

$1 a$<smiles>COC(=O)CC(C)C(C)C</smiles>

$2 a$<smiles>CC(C)(C)C(C)(C)C</smiles>

$3 a$

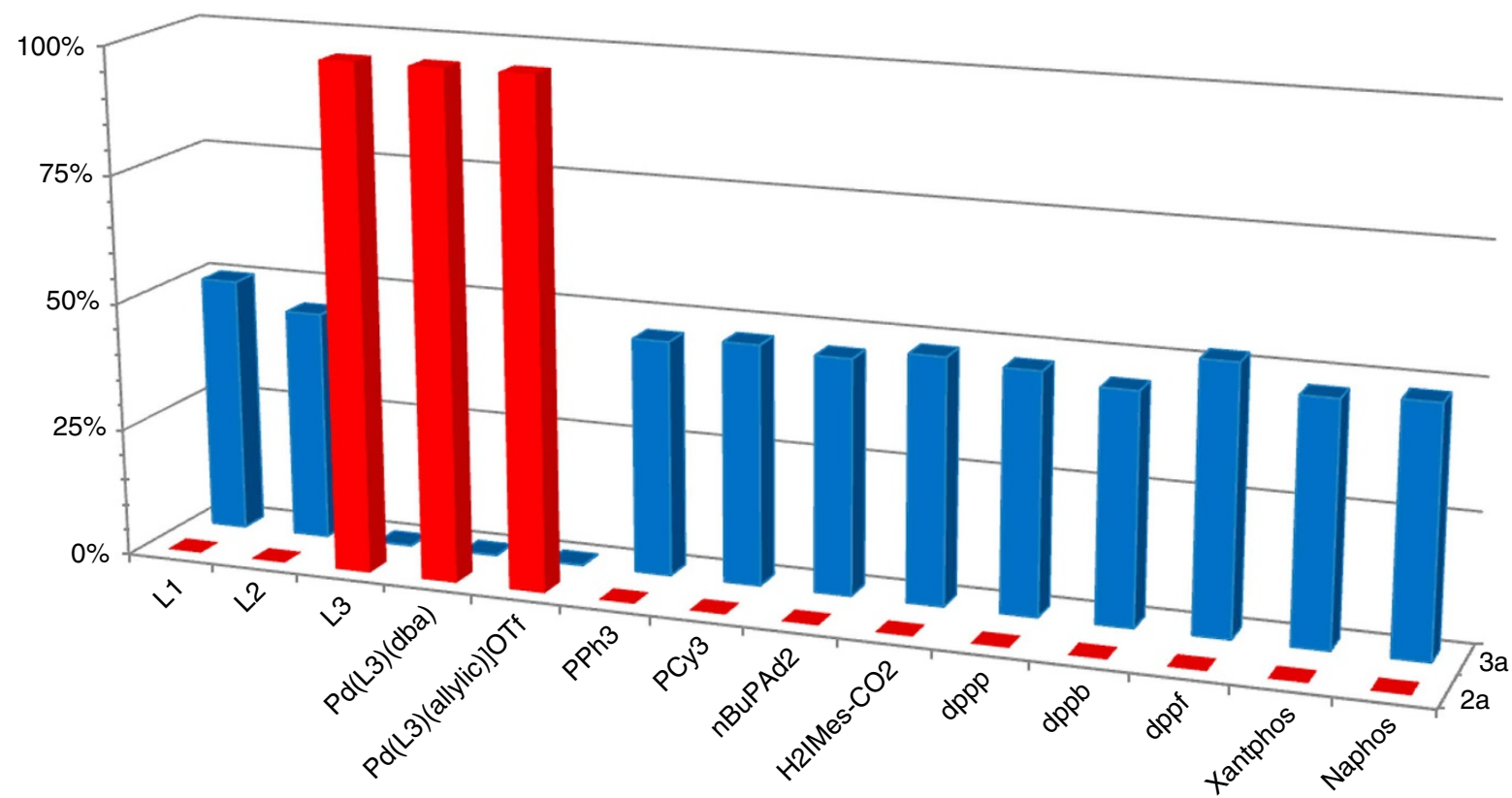

a

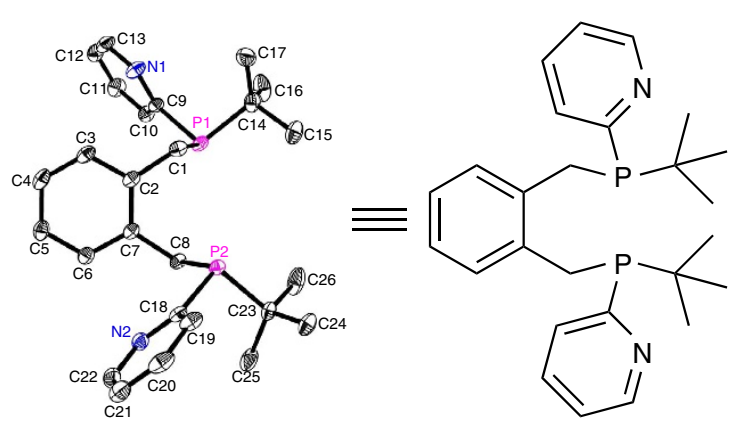

L3 (pytbpx)

b

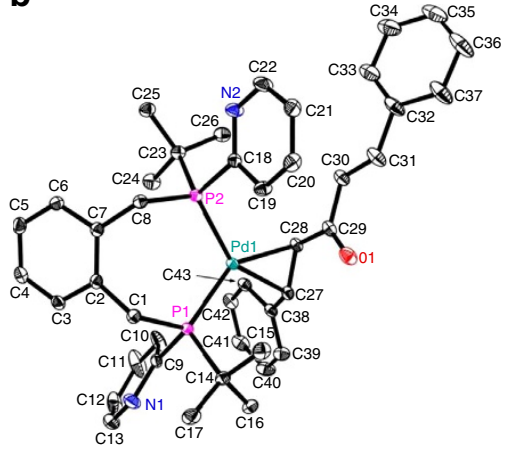

$\operatorname{Pd}(\mathbf{L} \mathbf{3})(\mathrm{dba})$
C

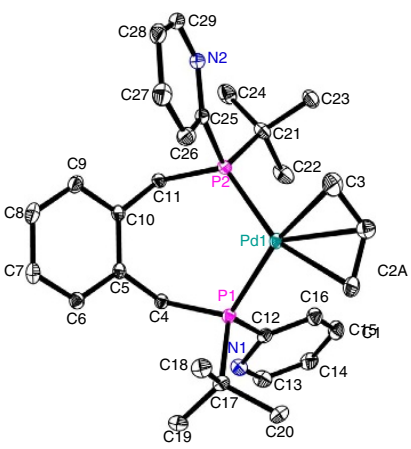

[Pd(L3)(allylic)]OTf

Figure 3 | Palladium-catalysed methoxycarbonylation of tetramethylethylene $\mathbf{1 a}$ in the presence of various ligands. Molecular structures of $\mathbf{L} \mathbf{3}$ and its palladium complexes: (a) $\mathbf{L} \mathbf{3},(\mathbf{b}) \mathrm{Pd}(\mathbf{L} \mathbf{3})(\mathrm{dba})$, and (c) $[\mathrm{Pd}(\mathbf{L} \mathbf{3})$ (allylic) $] \mathrm{OTf}$. Hydrogen atoms are omitted for clarity. Displacement ellipsoids correspond to $30 \%$ probability. Reaction conditions: 1 a $(4.0 \mathrm{mmol}), \mathrm{Pd}(\mathrm{acac})_{2}(0.1 \mathrm{~mol} \%)$, monodentate ligand $(0.8 \mathrm{~mol} \%)$, bidentate ligand $(0.4 \mathrm{~mol} \%)$, PTSA $(1.6 \mathrm{~mol} \%), \mathrm{CO}(40 \mathrm{bar}), \mathrm{MeOH}(2.0 \mathrm{ml}), 120^{\circ} \mathrm{C}, 20 \mathrm{~h}$. When Pd(L3)(dba) or $[\mathrm{Pd}(\mathbf{L} \mathbf{3})$ (allylic)]OTf was used, $\mathbf{L} 3(0.3$ mol\%) was introduced in the catalytic system. The conversion of $\mathbf{1} \mathbf{a}$ and the yields of $\mathbf{2} \mathbf{a}$ and $\mathbf{3} \mathbf{a}$ were determined by GC chromatography using iso-octane as the internal standard. acac, acetylacetonate; dba, dibenzylideneacetone; OTf, trifluoromethanesulfonate.

phthalimido 1o) in direct conjugation with the olefin led to functionalized esters in very good yield and regioselectivity. Notably, also methyl 2-acetamidoacrylate-an example of a notoriously unreactive push-pull olefin-produced the amino acid derivative $\mathbf{2 p}$ in $88 \%$ yield and highly selectively. Other olefins with remote substituents, for example, hydroxyl, nitrile, chloride and ester groups, underwent methoxycarbonylation smoothly and afforded the desired products $2 \mathbf{q}-\mathbf{t}$ in $65-96 \%$ yields, although in some cases the regioselectivity was lower. As an example for the carbonylation of renewable olefins (terpenes), we tested limonene. In contrast to known carbonylation catalysts ${ }^{40,41}$ double methoxycarbonylation occurred preferentially to deliver the diester product $\mathbf{2 u}$ in high yield.
Methoxycarbonylation of pharmaceuticals. For life science applications, the late-stage modification of lead compounds or even actual drugs is of current interest for the discovery of new bio-active agents. Using pharmaceuticals with inherent carboncarbon double bonds, our alkoxycarbonylation catalyst provides an entree to otherwise not easily accessible compounds. As depicted in Fig. 5, methoxycarbonylation of diethylstilbestrol-a potent anti-tumor drug-afforded the single regioisomer $2 \mathbf{v}$ in $92 \%$ yield, albeit as a mixture of diastereomers. As another example, cholesterol, which is an essential structural component of all animal cells that is required to maintain the structural integrity of membranes, is regioselectively carbonylated into the corresponding ester $\mathbf{2 w}$ in $81 \%$ yield. The molecular structure of 


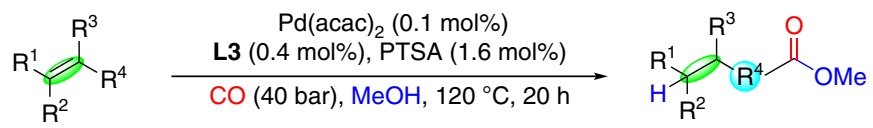

Steric hindrance: $R^{4}<R^{1}, R^{2}, R^{3}$

2a-w: yield, selectivity<smiles>COC(=O)CC(C)=C(C)C</smiles>

$2 a$

$2 b^{\mathrm{b}}: 94 \%\left(0 \%^{\mathrm{a}}\right)$

$98 \%\left(0 \%{ }^{\mathrm{a}}\right) \quad \mathbf{1} / \mathbf{2}=99 / 1$, syn/anti $=85 / 15$

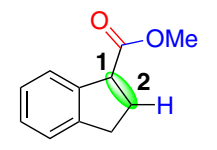

2c<smiles>COC(=O)C1=CCCCC1</smiles>

$\mathbf{2 d}^{\mathrm{C}} n=1: 96 \%$ $2 \mathbf{e}^{\mathrm{c}} n=3: 98 \%$

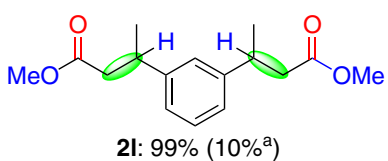

21: $99 \%\left(10 \%{ }^{a}\right)$<smiles>[R]C=CC(=O)OC</smiles>

$2 \mathrm{~m} \mathrm{R}=\mathrm{SiEt}_{3}: 88 \%, n /$ iso $=>99 / 1$ 2n $\mathrm{R}=n \mathrm{C}_{8} \mathrm{~F}_{17}: 99 \%, n /$ iso $=>99 / 1$

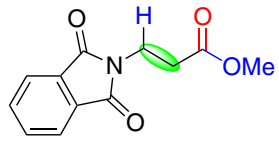

2o: $99 \%, n /$ iso $=>99 / 1$

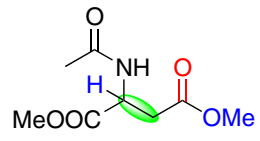

2p: $88 \%\left(0 \%^{a}\right), n /$ iso $=>99 / 1$

$$
\mathrm{R}_{\mathrm{H}_{3}}^{\mathrm{H}} \stackrel{\mathrm{O}}{\mathrm{O}} \mathrm{OMe}
$$

2q R $=\mathrm{CH}_{2} \mathrm{OH}: 80 \%, n /$ iso $=66 / 34$ 2r R $=\mathrm{CN}: 65 \%\left(0 \%{ }^{\mathrm{a}}\right), n /$ iso $=84 / 16$ 2s $\mathrm{R}=\mathrm{CH}_{2} \mathrm{Cl}: 91 \%\left(0 \%{ }^{\mathrm{a}}\right), n /$ iso $=70 / 30$

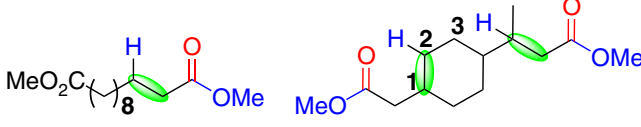

2t: $96 \%, n /$ iso $=72 / 28 \quad 2 \mathbf{u}^{\mathrm{d}}: 85 \%\left(5 \%^{\mathrm{a}}\right), \mathbf{1} /(\mathbf{2}+\mathbf{3})=56 / 44$

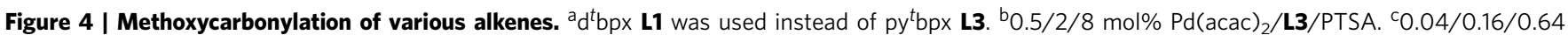
mol\% Pd(acac) $2 /$ L3/PTSA. ${ }^{1} 1 / 4 / 16$ mol\% Pd(acac) $2 /$ L3/PTSA. Isolated yields for all products.<smiles>CCC(CC)=C(CC)c1ccc(O)cc1</smiles>

Diethylstilbestrol

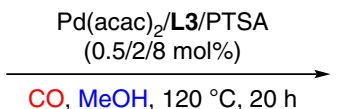

$\mathrm{HO}$<smiles>CCC(=C(CCC(=O)OC)c1ccc(O)cc1)c1ccc(O)cc1</smiles>

2v: $92 \%\left(0 \%^{\mathrm{a}}\right), n /$ iso $=>99 / 1, \mathrm{dr}=67 / 33$<smiles>CC(C)CCC[C@H](C)[C@H]1CC[C@H]2[C@H]3CC#CC4=C[C@H](O)CC[C@]4(C)[C@H]3CC[C@@]21C</smiles>

Cholesterol
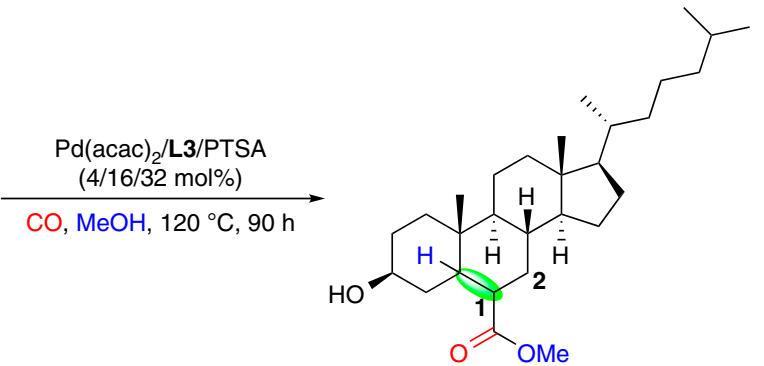

2w: $81 \%\left(0 \%^{\mathrm{a}}\right), \mathbf{1 / 2}=>99 / 1, \mathrm{dr}=54 / 46$

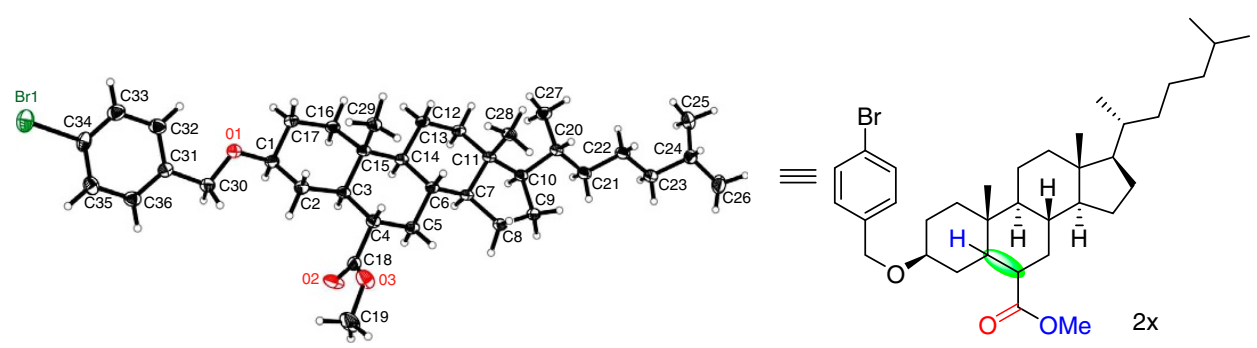

Figure 5 | Methoxycarbonylation of pharmaceuticals. ${ }^{a} d^{t} b p x \mathbf{L 1}$ was used instead of py ${ }^{t} b p x$ L3. Isolated yields for all products. 

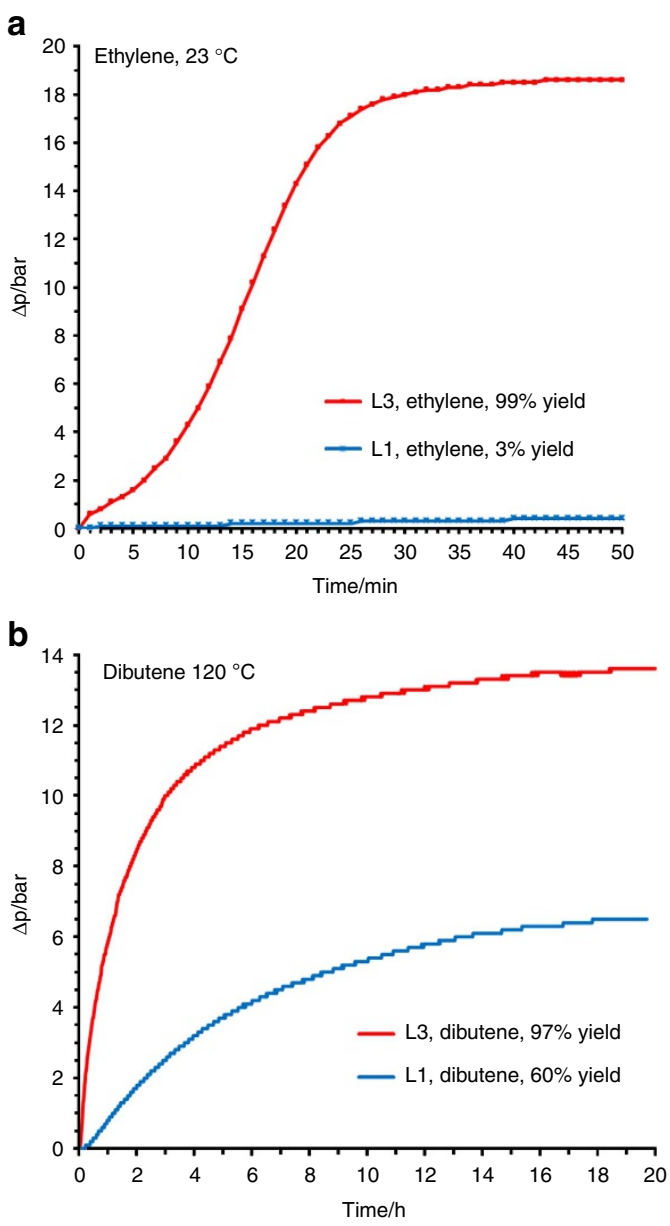

Figure 6 | Methoxycarbonylation of industrial bulk alkenes. Ethylene at $23^{\circ} \mathrm{C}$ (a) and dibutene at $120^{\circ} \mathrm{C}(\mathbf{b})$.

2w was confirmed by the X-ray diffraction of its derivative $\mathbf{2 x}$. Again, products $\mathbf{2 v}$ or $\mathbf{2 w}$ were not detected when using L1 instead of $\mathbf{L} 3$ under the same conditions.

Methoxycarbonylation of industrial bulk alkenes. The ultimate goal for any new catalyst is to be superior compared with known systems in 'real life' applications in industry. As mentioned vide supra, the methoxycarbonylation of ethylene constitutes a key step in the Lucite $\alpha$-process for the preparation of methyl methacrylate.

As depicted in Supplementary Fig. 12, important aliphatic olefins such as ethylene and propylene were completely converted to the corresponding methyl esters in quantitative yields in the presence of $\mathrm{Pd} / \mathrm{L} 3 / \mathrm{PTSA}(0.04 / 0.16 / 0.6 \mathrm{~mol} \%)$ at $80^{\circ} \mathrm{C}$ within $10 \mathrm{~min}$, respectively. Under such technical conditions, the new system again proved to be superior compared to the present stateof-the art industrial catalyst for such reactions. To demonstrate the striking difference in activity with the existing catalyst, ethylene was also methoxycarbonylated at room temperature. Using the commercial ligand $\mathbf{L} \mathbf{1}$ did not result in any catalyst activity, while $\mathbf{L} 3$ afforded the desired product within $30 \mathrm{~min}$ with excellent selectivity (>99\%) (Fig. 6a). To the best of our knowledge, this is also the first time that the methoxycarbonylation of ethylene proceeded at room temperature with significant rate. Remarkably, the catalyst loading can be decreased as low as 0.6 p.p.m. for ethylene methoxycarbonylation and the desired product was afforded with unprecedented activity and chemoselectivity (TON: $>1,425,000$; TOF: $44,000 \mathrm{~h}^{-1}$; total yield: $85 \%$, selectivity: $>99 \%$; Supplementary Methods).

As mentioned in the Introduction, another important industrial application is the alkoxycarbonylation of the feedstock dibutene. In contrast to ethylene, the key issue for this feedstock is to achieve full conversion, which is not yet possible due to the low reactivity of the inherent tetra-substituted olefins. To our delight, the new catalyst system allowed complete use of the substrate and the corresponding ester products were obtained in $97 \%$ yield (Fig. 6b). Again, this yield is unprecedented and such high conversion was not reported with any previously available catalyst systems.

In conclusion, we have developed a palladium catalyst based on the novel ligand $\mathbf{L 3}$ ( $\mathrm{py}^{t} \mathrm{bpx}$ ) for the general alkoxycarbonylation of olefins. With respect to reactivity, this catalyst clearly surpasses any known Reppe carbonylation catalyst in all applications studied so far. In addition to interesting synthetic examples, demanding challenging and industrially important bulk alkenes can be alkoxycarbonylated with unprecedented activity.

\section{Methods \\ Experimental procedures are described in Supplementary Methods in detail.}

Data availability. Crystal structures have been deposited at the Cambridge Crystallographic Data Centre and allocated the deposition numbers CCDC 1483958 (L3), 1483956 ([Pd(L3)(dba)]), CCDC 1483957 ([Pd(L3)(allylic)]OTf), and $1483955(\mathbf{2 x})$. Crystal data are also provided in Supplementary Tables 1-4. Spectra of products can be found in Supplementary Fig. 13. All other data are available from the authors upon reasonable request.

\section{References}

1. Hartwig, J. F. Organotransition Metal Chemistry: From Bonding to Catalysis (University Science Books, 2009).

2. Mueller, C. \& Vogt, D. Phosphinines as ligands in homogeneous catalysis: recent developments, concepts and perspectives. Dalton Trans. 47, 5505-5523 (2007).

3. Kollär, L. Modern Carbonylation Methods (Wiley-VCH, 2008).

4. Beller, M. Catalytic Carbonylation Reactions (Springer, 2006).

5. Beller, M., Cornils, B., Frohning, C. D. \& Kohlpaintner, C. W. Progress in hydroformylation and carbonylation. J. Mol. Catal. A Chem. 104, 17-85 (1995).

6. Franke, R., Selent, D. \& Börner, A. Applied hydroformylation. Chem. Rev. 112, 5675-5732 (2012).

7. Zbieg, J. R., Yamaguchi, E., McInturff, E. L. \& Krische, M. J. Enantioselective C-H crotylation of primary alcohols via hydrohydroxyalkylation of butadiene. Science 336, 324-327 (2012).

8. van Leeuwen, P. W. N. M. \& Claver, C. Rhodium Catalyzed Hydroformylation (Springer, 2000).

9. Kiss, G. Palladium-catalyzed reppe carbonylation. Chem. Rev. 101, 3435-3456 (2001).

10. Clegg, W. et al. Highly active and selective catalysts for the production of methyl propanoate via the methoxycarbonylation of ethene. Chem. Commun. 18, 1877-1878 (1999).

11. Eastham, G. R. et al. World Patent. WO2004014552A1 (2004).

12. Kissin, Y. in Alkene Polymerization Reactions with Transition Metal Catalysts (ed. Kissin, Y.) 17-28 (Elsevier Science, 2008).

13. Van Rooy, A., de Bruijn, J. N. H., Roobeek, K. F., Kamer, P. C. J. \& Van Leeuwen, P. W. N. M. Rhodium-catalysed hydroformylation of branched 1-alkenes; bulky phosphite vs. triphenylphosphine as modifying ligand. J. Organomet. Chem. 507, 69-73 (1996).

14. Andersson, P. G. \& Sharpless, K. B. A dramatic ligand effect on the relative reactivities of substituted alkenes with osmium tetroxide. J. Am. Chem. Soc. 115, 7047-7048 (1993).

15. Sharpless, K. B. \& Williams, D. R. The reactions of olefins with permanganate, ruthenium tetroxide, and osmium tetroxide; dependence of rate on degree of substitution. Tetrahedr. Lett. 16, 3045-3046 (1975).

16. Bond, G. C. \& Wells, P. B. in Advances in Catalysis vol 15 (eds Pines, H., Eley, D. D. \& Paul, B. W.) 91-226 (Academic Press, 1965).

17. Wender, I., Metlin, S., Ergun, S., Sternberg, H. W. \& Greenfield, H. Kinetics and mechanism of the hydroformylation reaction. the effect of olefin structure on rate1. J. Am. Chem. Soc. 78, 5401-5405 (1956).

18. Heil, B. \& Markó, L. Hydroformylierung von Olefinen mit RhodiumcarbonylKatalysatoren, II. Einfluß der Olefinstruktur auf die Reaktionsgeschwindigkeit. Chem. Ber. 102, 2238-2240 (1969). 
19. Knifton, J. F. Linear carboxylic acid esters from.alpha. olefins. 2. Catalysis by homogeneous palladium complexes. J. Org. Chem. 41, 2885-2890 (1976).

20. Keulemans, A. I. M., Kwantes, A. \& van Bavel, T. The structure of the formylation (OXO) products obtained from olefines and watergas. Recl. Trav. Chim. Pays. Bas 67, 298-308 (1948).

21. Vasseur, A., Bruffaerts, J. \& Marek, I. Remote functionalization through alkene isomerization. Nat. Chem. 8, 209-219 (2016).

22. Seayad, A. et al. Internal olefins to linear amines. Science 297, 1676-1678 (2002).

23. Li, H. et al. The scope and mechanism of palladium-catalysed Markovnikov alkoxycarbonylation of alkenes. Nat. Chem. 8, 1159-1166 (2016).

24. Xu, T., Sha, F. \& Alper, H. Highly ligand-controlled regioselective Pd-catalyzed aminocarbonylation of styrenes with aminophenols. J. Am. Chem. Soc. 138, 6629-6635 (2016).

25. Jimenez Rodriguez, C., Foster, D. F., Eastham, G. R. \& Cole-Hamilton, D. J. Highly selective formation of linear esters from terminal and internal alkenes catalysed by palladium complexes of bis-(di-tert-butylphosphinomethyl) benzene. Chem. Commun. 15, 1720-1721 (2004).

26. Roesle, P. et al. A comprehensive mechanistic picture of the isomerizing alkoxycarbonylation of plant oils. J. Am. Chem. Soc. 136, 16871-16881 (2014).

27. Busch, H., Stempfle, F., He, Grau, E. \& Mecking, S. Selective isomerizationcarbonylation of a terpene trisubstituted double bond. Green Chem. 16, 4541-4545 (2014).

28. Ye, F. \& Alper, H. Recyclable selective palladium-catalyzed synthesis of fivesix- or seven-membered ring lactones and lactams by cyclocarbonylation in ionic liquids. Adv. Synth. Catal. 348, 1855-1861 (2006).

29. Tooze, R. P., Eastham, G. R., Whiston, K. \& Wang, X. L. Carbonylation of ethylene and stable catalyst system containing bidentate phosphine compounds. World Patent WO9619434A1 (1996).

30. Crawford, L., Cole-Hamilton, D. J., Drent, E. \& Bühl, M. Mechanism of alkyne alkoxycarbonylation at a pd catalyst with p,n hemilabile ligands: a density functional study. Chem. Eur. J. 20, 13923-13926 (2014).

31. Reetz, M. T., Demuth, R. \& Goddard, R. 2-Pyrimidylphosphines: A new class of ligands for transition metal catalysis. Tetrahedr. Lett. 39, 7089-7092 (1998).

32. Nunez Magro, A. A. et al. Highly selective formation of unsaturated esters or cascade reactions to [small alpha],[small omega]-diesters by the methoxycarbonylation of alkynes catalysed by palladium complexes of 1,2-bis(ditertbutylphosphinomethyl)benzene. Chem. Sci. 1, 723-730 (2010).

33. Drent, E., Arnoldy, P. \& Budzelaar, P. H. M. Homogeneous catalysis by cationic palladium complexes. Precision catalysis in the carbonylation of alkynes. J. Organomet. Chem. 475, 57-63 (1994).

34. Drent, E., Arnoldy, P. \& Budzelaar, P. H. M. Efficient palladium catalysts for the carbonylation of alkynes. J. Organomet. Chem. 455, 247-253 (1993).

35. Crawford, L., Cole-Hamilton, D. J. \& Buehl, M. Uncovering the mechanism of homogeneous methyl methacrylate formation with p,n chelating ligands and palladium: favored reaction channels and selectivities. Organometallics 34, 438-449 (2015).

36. Eastham, G. R. et al. Synthesis and spectroscopic characterisation of the intermediates in the Pd-catalysed methoxycarbonylation of ethene. Chem. Commun. 7, 609-610 (2000).

37. Clegg, W. et al. Characterization and Dynamics of $[\mathrm{Pd}(\mathrm{L}-\mathrm{L}) \mathrm{H}($ solv $)]+$, $\left[\mathrm{Pd}(\mathrm{L}-\mathrm{L})\left(\mathrm{CH}_{2} \mathrm{CH}_{3}\right)\right]+$, and $[\mathrm{Pd}(\mathrm{L}-\mathrm{L})(\mathrm{C}(\mathrm{O}) \mathrm{Et})(\mathrm{THF})]+(\mathrm{L}-\mathrm{L}=1,2-$ $\left.\left(\mathrm{CH}_{2} \mathrm{PBut}_{2}\right)_{2} \mathrm{C}_{6} \mathrm{H}_{4}\right)$ : Key Intermediates in the Catalytic Methoxycarbonylation of Ethene to Methylpropanoate. Organometallics 21, 1832-1840 (2002).
38. Roesle, P. et al. Mechanistic Features of Isomerizing Alkoxycarbonylation of Methyl Oleate. J. Am. Chem. Soc. 134, 17696-17703 (2012).

39. van Leeuwen, P. W. N. M. et al. Alcoholysis of acylpalladium(ii) complexes relevant to the alternating copolymerization of ethene and carbon monoxide and the alkoxycarbonylation of alkenes: the importance of cis-coordinating phosphines. J. Am. Chem. Soc. 125, 5523-5539 (2003).

40. da Rocha, L. L., Dias, A. D., dos Santos, E. N., Augusti, R. \& Gusevskaya, E. Palladium/tin catalyzed alkoxycarbonylation of naturally occurring bicyclic monoterpenes. J. Mol. Catal. A Chem. 132, 213-221 (1998).

41. Naigre, R. et al. Carbon monoxide as a building block in organic synthesis. Part V. Involvement of palladium-hydride species in carbonylation reactions of monoterpenes. X-ray crystal structure of $\left[\mathrm{Ph}_{3} \mathrm{PCH}_{2} \mathrm{CH}=\mathrm{CHPh}\right]_{4}\left[\mathrm{PdCl}_{6}\right]$ [SnCl 6 . J. Organomet. Chem. 480, 91-102 (1994).

\section{Acknowledgements}

This work is supported by the State of Mecklenburg-Vorpommern and Evonik Performance Materials GmbH. K.D. appreciates Shanghai Institute of Organic Chemistry-Zhejiang Medicine joint fellowship. X.F. thanks Chinese Government Award for Outstanding Self-Financed Students Abroad. We also thank the analytical team for kind support and the insightful discussion with Prof. Haijun Jiao and Dr Haoquan Li.

\section{Author contributions}

M.B., K.D. and F.X. conceived and developed the project on the alkene alkoxycarbonylations. K.D., F.X., H.N. and S.G. prepared the catalyst and performed the catalytic experiments. M.B. and K.D. wrote the manuscript with revisions provided by R.J., R.F. and A.S.

\section{Additional information}

Supplementary Information accompanies this paper at http://www.nature.com/ naturecommunications

Competing financial interests: Related patent applications have been filed by Evonik Performance Materials GmbH. S. Gülak, R. Franke, A. Spannenberg are not declaring COI.

Reprints and permission information is available online at http://npg.nature.com/ reprintsandpermissions/

How to cite this article: Dong, K. et al. Highly active and efficient catalysts for alkoxycarbonylation of alkenes. Nat. Commun. 8, 14117 doi: 10.1038/ncomms14117 (2017).

Publisher's note: Springer Nature remains neutral with regard to jurisdictional claims in published maps and institutional affiliations.

This work is licensed under a Creative Commons Attribution 4.0 International License. The images or other third party material in this article are included in the article's Creative Commons license, unless indicated otherwise in the credit line; if the material is not included under the Creative Commons license users will need to obtain permission from the license holder to reproduce the material. To view a copy of this license, visit http://creativecommons.org/licenses/by/4.0/

(C) The Author(s) 2017 